\title{
ENSINAR LITERATURA: A QUE SERÁ QUE SE DESTINA?
}

Em memória do Prof. Luiz Dantas.

\author{
Caio Gagliardi \\ caiogagliardi@gmail.com
}

1.

Ministro na Universidade de São Paulo uma disciplina ligada ao tema que debaterei aqui. A minha intenção é discutir o ensino da literatura. Há uma série de estudos críticos relacionados a diferentes aspectos desse tema, alguns deles difíceis de contornar pela clareza e pelo desenvolvimento da reflexão que propõem. É necessário que o diga porque, embora sejam trabalhos edificadores da visão de ensino aqui presente, optei por não nomeá-los neste texto. Essa omissão é um apagamento, mas também um modo de liberar outras vozes. O que de fato se manifesta nas próximas linhas é resultado mais direto dessa experiência de ensino a que me referi. ${ }^{1}$ Dela decorre igualmente a forma deste ensaio - um ensaio de vozes, mais precisamente -, que visa trazer a lume não a concepção de quem ensina, mas daqueles que aprendem. As opiniões dos estudantes apresentam uma legitimidade própria e podem nos ensinar a prosseguir nesse debate.

Em minhas aulas, depois de ler e analisar textos a respeito desse e de assuntos análogos a esse, propus aos estudantes um exercício a ser realizado em sala. A atividade consistiu no seguinte: ler um artigo,

${ }^{1}$ Adisciplina a que me refiro intitula-se “Literatura Portuguesa:ensino-aprendizagem”. 
publicado no jornal Folha de São Paulo, intitulado "Repensando o ensino da literatura", assinado por um professor doutor em Linguística pela USP e, em seguida, redigir uma carta-resposta, dirigida ou ao jornal ou ao próprio autor. A atividade, restrita aos cem minutos de duração da aula, seria complementada, na aula seguinte, pela discussão dos argumentos elaborados pelos próprios alunos em suas cartas, e, no final, pela apresentação de uma carta redigida por mim.

A minha intenção com esse exercício não foi, esteja claro, expor ao debate o autor do artigo. $\mathrm{O}$ que levei à discussão foram as ideias contidas ali, por julgá-las exemplares de uma certa concepção de ensino, e de literatura, que ilustra, com a mesma ou maior eficácia com que ilustrava no momento de sua publicação, o lugar conferido ao texto literário nos currículos escolares. Cabe ainda salientar que a referida carta que redigi nunca foi lida em sala de aula. Antes, preferi ler e comentar trechos das cartas que os próprios alunos haviam escrito, por trazerem ricos e, por vezes, surpreendentes argumentos para o debate.

Para que o leitor possa nos acompanhar (é inevitável, a essa altura, o uso do plural, uma vez que, como ficará claro nas próximas páginas, a autoria deste texto é coletiva), transcrevo abaixo o artigo publicado no referido jornal, e que motivou todo o debate.

[Repensando o ensino de literatura.]

Como todos sabem, o ensino de literatura portuguesa e brasileira faz parte do currículo escolar de primeiro e segundo graus, e o conhecimento dessas literaturas é exigido na maioria dos concursos vestibulares. A justificativa para o ensino dessas disciplinas é a necessidade de nossos jovens tomarem contato com a literatura e, assim, com a língua portuguesa escrita em sua mais alta expressão. Em suma, o conhecimento literário faz parte da formação geral e humanística que se espera de qualquer cidadão escolarizado.

No entanto, o ensino de literatura nas escolas tem-se restringido, as mais das vezes, à história da literatura brasileira e portuguesa, exigindo do aluno, por exemplo, que decore o fato de que o início do romantismo no Brasil se deu com a publicação, em 1836, de «Suspiros Poéticos e Saudades», de Gonçalves de Magalhães, ou que o barroco se caracterizava, dentre outras coisas, pelo teocentrismo. Paralelamente, exige-se a leitura de alguns livros enfadonhos, como, por exemplo, os de José de Alencar, que não servem, atualmente, como modelo de estilo literário nem de uso linguístico do português.

Ora, a literatura é uma arte como qualquer outra, como a música, a pintura, a escultura, o teatro. Entretanto o ensino de educação artística nas escolas não se restringe à história da arte, mas, antes, procura incentivar a criatividade dos alunos por meio da elaboração de trabalhos manuais. Igualmente, o ensino de música (nas escolas onde ele existe) não objetiva fazer os alunos saberem em que ano nasceu Beethoven, mas sim transmitir a eles os rudimentos de teoria musical e de prática de algum instrumento. Note-se que nem o conhecimento 
de música nem o de artes é exigido nos vestibulares (exceto, é claro, para as carreiras de música e de artes plásticas).

Assim, se o conhecimento das outras artes não é pré-requisito para a maioria das carreiras universitárias, por que o de literatura o é? A meu ver, o conhecimento literário só deveria ser exigido dos candidatos ao curso de letras (mesmo assim, se um estudante universitário de inglês só estuda a literatura dessa língua na faculdade, não seria o caso de um estudante de português aprofundar-se na história das literaturas de língua portuguesa também na faculdade, em vez de fazê-lo no colégio?). Se o objetivo do ensino de literatura na escola média é estimular no aluno o hábito da leitura, então, por que, em vez de obrigá-lo a ler obras de ficção de séculos passados, não se propõe a ele a leitura de obras importantes de não-ficção da atualidade, como os livros de Sérgio Buarque de Hollanda e Milton Santos, por sinal muito bem escritos, ou os de Carl Sagan, que possuem, aliás, excelentes traduções em português? Será que o estudo de obras, nacionais ou estrangeiras, que tratam de questões reais do mundo contemporâneo, como a globalização e a poluição, por exemplo, não é mais relevante que o estudo de obras ficcionais? No meu entender, o conhecimento de literatura não é mais importante do que o de outras formas de manifestação artística nem deveria ser privilegiado em detrimento das demais artes. Além disso, em termos culturais, a literatura universal, com Dante, Goethe, Rousseau, Dickens e Joyce, dentre outros, é tão importante quanto a literatura de língua portuguesa. Por outro lado, a literatura é um dos produtos da língua, mas não o único nem o mais importante (parece-me que a principal função da linguagem é permitir a comunicação pragmática entre os seres humanos, e não produzir literatura). Assim, por que a leitura dos estudantes deve se dar apenas sobre a literatura de ficção e não sobre jornais, revistas e livros de não-ficção? E por que os exames vestibulares não exigem dos candidatos à universidade cada vez mais o domínio de uma cultura geral, indispensável a qualquer profissional de nível superior, em lugar de cobrar deles apenas o conhecimento histórico da literatura portuguesa e brasileira? [BIZZOCHI, 20oo]

2.

Não sem razão, a radiografia do ensino que abre a reflexão presente nesse artigo revela dois problemas inerentes ao modo como a literatura é abordada na escola: 1 . geralmente, seu ensino limita-se ao historicismo literário e 2. o corpus estudado restringe-se às literaturas brasileira e portuguesa. É de suma importância, tal como sugerido pelo título do artigo, e com base justamente nessas duas constatações, repensar o ensino da literatura no país. A propalada "crise da literatura", inserida no espectro mais largo do ensino das humanidades, talvez tenha maior relação com o modo como ela é ensinada do que, afinal, com a literatura em si mesma. No entanto, o que poderia sugerir, a partir da identificação do problema, algum novo rumo, na verdade é impulso para um recuo da reflexão. Se a literatura, como qualquer outra arte, não se limita ao que é objeto do estudo histórico dela, fecundo seria pensar como ela pode deixar de ser 
apenas isso nas escolas, para alunos e professores, como tem sido quase sempre. Mas outros preferirão a retirada da literatura das escolas, já que varrido para debaixo do tapete o problema parece resolvido. ${ }^{2}$

De modo alarmante, muitas das tentativas de se repensar o ensino da literatura no Brasil, incluindo os documentos oficiais destinados a esse fim, têm partido de professores e coordenadores, em sua maioria, de outras áreas, e resultado em iniciativas para se dispensá-la gradativamente. Não é de se estranhar. Uma concepção de ensino que seja formulada à distância daquilo que se pretende ensinar tende a conferir à matéria ensinada um tratamento fundamentalmente instrumental. O que está em jogo de modo explícito nesse 'repensar' é o caráter estritamente funcional do ensino, o qual não deixa de refletir a construção, ainda positivista, da nossa sociedade. ${ }^{3}$ A literatura não é, certamente, uma forma mais fácil de aprender história ou sociologia. Para esse fim há textos mais eficientes do que os ficcionais. O que intriga é considerar que, não servindo bem a esse propósito, passa a não ter serventia. A compreensão de que é a própria experiência literária que está em jogo, e não uma imperfeita imitação da realidade, pode parecer simples para aqueles que de fato descobriram o valor das artes em suas vidas, mas é um duro obstáculo aos que se sentem mais despertados por um texto dito "objetivo".

A "cultura geral", por mais que seja útil, apenas reafirma o real e o conhecido, ao passo que a literatura o questiona e expande os horizontes do leitor, ensinando-o a enxergar verdades ocultas pelo real, ressignificando cada elemento seu. Os livros de ficção instauram uma realidade à parte, que nos leva, necessariamente, a nos distanciarmos da realidade nossa de cada dia. A literatura permite-nos ver as múltiplas verdades que residem no âmago de cada experiência. Ao adentrar a mente de um eu lírico ou de um narrador, vivo, por instantes, uma vida que não é minha e, ao deixála, saio transformado e conhecedor de singularidades humanas que me escapavam por completo. ${ }^{4}$

É igualmente visível a presença, nesse modo de "repensar" o ensino, de uma forte desconfiança do valor das artes, e da literatura principalmente, como algo realmente formativo, uma vez que a ênfase da argumentação sobre a ineficácia de tal ensino recai sobre as exigências dos vestibulares. ${ }^{5}$ Trata-se do pensamento já bem arraigado de que o que se aprende na escola ou o motivo de se aprender algo depende do vestibular. Este parece ter se tornado o pólo gravitacional do ensino brasileiro. ${ }^{6}$

\footnotetext{
${ }^{2}$ Carta de Mateus Ramos Lourenço.

3 Ibid.

${ }^{4}$ Carta de João Henrique Lara Ganança.

${ }_{5}^{5}$ Carta de Daiane Walker Araujo.

${ }^{6}$ Carta de Alex Mazzanti Júnior.
} 
Ora, essa visão limita o alcance desse mesmo ensino, por apegar-se ao que haja de estritamente objetivo no conhecimento humano. O conhecimento literário não é objetivo (embora a noção de 'cânone’ nos dê essa impressão). Trata-se, antes, do desenvolvimento de um "modo de ver", ou seja, de um olhar investigativo que nos leva a enxergar para além da aparência do já conhecido. Nesse sentido, a literatura não é útil, porque não encaminha a um objeto específico, e não é pedagógica, porque nos faz repensar e rever nossas ideias feitas sobre o mundo e as coisas. Parece perigoso, não? Para quê, afinal? É tarefa do professor estimular esse tipo de insubmissão?7

A bem considerar, não se ensina literatura; ensina-se com literatura. $\mathrm{O}$ que a literatura ensina não se pode descrever como mera transferência de conhecimento. Não se trata de um conteúdo mensurável, e sim de uma vivência potencialmente depuradora da atenção, da percepção, da consciência, da reflexão e dos afetos. Mais próxima, portanto, de uma experiência transformadora do que de uma disciplina propriamente dita, a literatura, ela mesma, é que ensina.

É, por esse motivo, prerrogativa do professor de literatura, mais do que dos educadores, colocar em questão certas práticas relacionadas ao ensino dessa disciplina, hoje, no Brasil.

O que se percebe no artigo que motiva essa discussão é, entretanto, não a problematização, mas a proposta de supressão desse ensino. Não passa despercebido, inclusive, o preconceito com relação ao rótulo 'literatura', que é aplicado como se trouxesse aos textos certo tom de algo dispensável, uma vez que há mais coisas 'úteis' a se ensinar e a se aprender. Pouco se fala, no entanto, sobre a "utilidade" de um trinômio ou um balanceamento de equações químicas, mas constantemente vêm à tona questões ligadas a uma provável e bastante suspeita "não utilidade" da literatura, seja ela qual for. $O$ debate a respeito do ensino em geral, e não só da literatura, não deveria ser encaminhado justamente para o lado utilitário: a escola (ainda) é o lugar da formação, não da instrumentalização de indivíduos. Formar um sujeito leitor em sua completude (isto é, de textos ficcionais e não-ficcionais) deveria ser tão importante quanto um sujeito que entenda de cálculos e proporções. ${ }^{8}$

Ora, é absolutamente lógico esperar que muitas manifestações artísticas tenham sido censuradas por regimes antidemocráticos. Sua força subversiva, relacionada à capacidade de despertar as consciências, não foi menosprezada por esses mesmos regimes. Alarme verdadeiro causa esse tipo de proposição quando articulada por pessoas letradas, vivendo num regime político comprometido com a igualdade e a liberdade entre os cidadãos.

${ }^{7}$ Carta de Daiane Walker Araujo.

${ }^{8}$ Carta de Fernanda Capraro de Toledo. 
Em primeiro lugar, o acesso ao cânone literário é um direito de todo indivíduo. Trata-se de uma bagagem cultural que lhe permitirá conhecer uma tradição, não apenas nacional, mas universal, de referências culturais que orientavam e orientam valores. Isso é extremamente benéfico para o aluno, na medida em que seu olhar crítico sobre a tradição lhe permitirá interrogá-la e reavaliá-la. Nesse sentido, não se trata de questionar por que os vestibulares exigem conhecimento literário do aluno, mas sim que tipo de conhecimento vem sendo exigido. Assim como o saber científico faz parte dos pré-requisitos para o ingresso à universidade, o conhecimento literário não deve ter menos importância. ${ }^{9}$

Se considerarmos, afinal, a ausência das demais artes nos currículos escolares, cujo ensino não é cobrado, por que não concluirmos em favor de agregá-las aos currículos, ao invés de, seguindo-se o mau exemplo, eliminar desses currículos também a literatura? Não há motivo para compensarmos a falta das outras excluindo também a literatura e fazendo com que o estudante tenha ainda menos contato com o mundo das artes. Ainda que seja desejável a inclusão de outras formas de arte, que não exclusivamente a literária, nos currículos, é preciso levar em conta a esse respeito que a literatura tem sim um papel mais específico do que as demais no processo de formação do indivíduo que passa pela escola. Essa consideração não depende, que fique claro, de uma atribuição de valor, porque se sustenta numa das características definidoras desses mesmos currículos: a escola não é ensino técnico, mas ensino letrado, da cultura letrada como um todo. ${ }^{10}$ Chama a atenção, por isso mesmo, que esse hiato esteja presente nos Parâmetros Curriculares Nacionais para o Ensino Médio. Nesse documento, a palavra literatura, substituída no título por "Linguagens, Códigos e suas Tecnologias", aparece sem especificidade, na maior parte das vezes acompanhada pelas artes plásticas, pela música, pelo teatro e pela dança, como mais um exemplo de produção artística. Ali, ela não é abolida dos currículos, mas incluída sem nenhuma ênfase.

A perspectiva segregacionista do ensino empenha-se, desde cedo, em isolar os indivíduos em grupos, cada qual sabedor apenas de uma área de conhecimento. Relegar o ensino da literatura apenas a estudantes de Letras significa restringir ao menor contingente possível o contato com uma visão desautomatizada da realidade e com um repositório de riqueza ilimitada de usos da língua, que vai muito além daquela única função que o autor do referido artigo atribui à linguagem, a comunicativa. Curioso notar que Jakobson, um dos linguistas eminentes do século XX,

9 Carta de Daiane Walker Araujo.

${ }^{10}$ Carta de Julia Garcia. 
ao identificar como "função comunicativa" esse importante papel da linguagem, não a hierarquiza acima de uma outra função, a poética, que, entretanto, insiste-se em menosprezar.

Sei pouco de Física, mas o suficiente para saber que o princípio da bomba atômica e da geração de energia nuclear é o mesmo. O que muda, então? O que faz com que o mesmo princípio físico faça viver ou gere uma grande catástrofe? É a pessoa quem constrói o mecanismo, não é? Isso me faz pensar que o ingressante no curso de Física na universidade tem de saber matemática, mas também tem de ter discutido o significado da "Anti-Rosa atômica", de que fala Vinícius. O futuro engenheiro responsável por obras de irrigação no Nordeste precisa de cálculos, obviamente, mas talvez seja determinante que ele tenha lido Vidas Secas. Um futuro juiz pode repensar o Direito se ler atentamente Dom Casmurro, pode definir uma sentença de maneira diferente se tiver lido "Mineirinho", de Clarice Lispector, pode mudar o rumo de uma vida ao se emocionar com "Morte e Vida Severina."

A proposta de afastamento da Literatura do ensino médio parece flertar com uma lógica bastanteconhecidadenóstodos. Aodestacara(ir)-relevância de determinado objeto para se atingir determinado fim, isto é, a qualificação de um "profissional de nível superior", é possível deduzir que se passa a compartilhar da lógica de mercado, que enxerga o ensino como formação de mão-de-obra qualificada, distorcendo, enfim, o pensamento em torno da literatura como formadora do humano. ${ }^{12}$ Não é de surpreender que o ensino da literatura esteja em crise. Visto que a literatura é, fundamentalmente, um valor que se atribui a uma determinada forma de linguagem, ela está sujeita às leis da valorização que são típicas do setor predominante da moderna vida social: o econômico. Ao lermos, nesse contexto específico, que "a literatura é um produto da língua”, ${ }^{13}$ deparamo-nos com essa mesma lógica de mercado ditando os rumos da cultura e do ensino. E não será, aliás, por ser uma forma de atender a uma crescente demanda de produtividade que o historicismo, condenado no início do referido artigo, continua a determinar a perspectiva do ensino da literatura no país?

O ensino da literatura caiu no 'historicismo' porque é a única forma de mostrar produtividade nas avaliações cartesianas da escola; porque '1836 + Suspiros poéticos e saudades = Romantismo no Brasil'. Essa é a maneira mais fácil de assemelhar esse ensino à linguagem do '2+2=4', que se deve seguir nas ciências ditas úteis. ${ }^{14}$

\footnotetext{
${ }^{11}$ Carta de Flávia Capraro de Toledo.

${ }^{12}$ Carta de Nara Lasevicius Carreira.

${ }^{13}$ A citação e o grifo são de Luana Barossi.

${ }^{14}$ Carta de Flávia Capraro de Toledo.
} 
Quando passamos a superestimar o novo em detrimento do velho, e o real em detrimento do ficcional, argumentamos como consumidores ávidos por aquilo que podem ver e tocar, descartando o que ficou obsoleto, superado. O processo de materialização da cultura orienta-se, afinal, pela lei do menor esforço. Por esse modo de enxergar a literatura, caberá a romances "como, por exemplo, os de José de Alencar", o rótulo de "enfadonhos".

Será, entretanto, que não há nada de interessante numa obra tida como enfadonha? Será que um estudante de música, cujo repertório seja completamente popular, se empolga de imediato ao ouvir Beethoven ou Ravel? Evidente que não. Não se pode desconsiderar que numa obra literária há diversas forças que se mobilizam: a imaginação, a capacidade de leitura e releitura, a surpresa do léxico, o encantamento com o som do agrupamento das palavras, a empatia com personagens, as novas formas de ver, sentir e estar no mundo. Não será preciso que um pobre estudante de graduação diga que essas forças não são formadoras somente dos estudantes de Letras, mas sim da própria constituição do ser humano. Dessa forma, me parece que restringir o literário ao estudante universitário de literatura não seria adequado. ${ }^{15}$

Para além do qualificativo de alcance pessoal - enfadonho é algo que aborrece, incomoda, molesta -, chama a atenção a justificativa que baliza tal juízo de valor: muitas obras "não servem, atualmente, como modelo de estilo literário nem de uso linguístico do português." É natural que, enxergando a literatura como produto, e não como produtora, passe-se a considerar muitas das obras do passado como produtos ultrapassados. A mesma lógica poderia se aplicar, afinal, a autores mais antigos que Alencar, e cujo estilo encontra-se ainda mais distante do atual. Servirão "Dante, Goethe, Rousseau e Dickens", além de "Joyce", também citado na carta, como modelos de uso linguístico atual em seus países? Serão suas obras menos "enfadonhas" ao estudante do ensino médio do que as de Alencar? E como poderiam, afinal, ser ao menos acessíveis a esse estudante, se o que se propõe é, em seu lugar, o ensino "de obras importantes de não-ficção da atualidade"? Em síntese: realidade e atualidade - eis o binômio que embasa, com pretensa exclusividade, o sistema de valores de um homem útil, produtivo e pragmático. Será mesmo esse o homem que queremos formar? O homem em que queremos nos tornar?

Os alunos estão cheios de realidade, fartos, entorpecidos, tagarelas dela. E isso não só na própria escola, onde falar de temas atuais como "poluição" e "globalização" é o grito da moda, como nas ruas, nas rádios, nos cartazes, nos reclames, nas tevês e nos jornais. ${ }^{16}$ Algo relacionado à nossa própria constituição não terá sido deixado para trás?

${ }^{15}$ Carta de Felipe Pimenta.

${ }^{16}$ Carta de Silas Sampaio Garcia. 
A leitura de um jornal com notícias do cotidiano não exclui a necessidade de contato com a expressão artística, nem o contrário ocorre. Fosse assim, um pai leria a seus filhos, antes de dormirem, receitas de bolo, informes de marketing e prospectos bancários, fazendo com que dormissem fascinados e que pedissem uma repetição da leitura na noite seguinte. ${ }^{17}$

O ficcional e o extemporâneo. Quem sabe, a nossa ânsia de estarmos objetivamente compromissados com o que nos cerca não nos esteja levando ao descompromisso com a nossa subjetividade? Quem realmente sério ousaria dizer que o que está faltando não são Milton Santos ou Sérgio Buarque de Hollanda, em que pese a importância que têm na formação de qualquer indivíduo, mas sobretudo mais imaginação às escolas?

Diria até que, de tanto reformularmos incessantemente o currículo, de tanto deixá-lo "atual", já não há, a rigor, diferença entre aquilo que é visto dentro ou fora da escola. A sala de aula não traz novidades, não há nada lá que não esteja cá. Talvez daí o sem sentido, ou a dita crise escolar. Que vão fazer lá as crianças? Se alguma possibilidade me parece interessante, é a de que a escola seja um lugar onde algo aconteça. E tal não seria possível sem que se proponha a quem a frequenta uma experiência, algo desconhecido, algo novo. Ora, esse novo, quem diria, poderia ser José de Alencar. Por que não? ${ }^{18}$

Levada ao limite, a problematização do ensino da literatura tende a ultrapassar o limiar metodológico que circunscreveria um debate humanista, para esboçar outros questionamentos, distantes do rigor que a discussão reclama, sobre o papel ou a serventia da literatura. Não é essa uma indagação recente, e não será o momento, até por isso, de lembrar as muitas respostas que suscitou através dos séculos. É sintomático, entretanto, que essa pergunta tenha voltado a ser feita no atual momento histórico. Valerá, quem sabe, respondê-la, não com outra resposta, mas com outra pergunta, de formulação também conhecida: Existirmos, a que será que se destina?

Ainda resta algo de "não útil" no mundo, algo que não é "inútil", mas efetivamente tem pouca aplicação cotidiana ou concreta: resta à literatura a "não utilidade" de existir. É justamente por isso que se deve discutir seu ensino, pois a escola forma sujeitos dispostos à socialização, não apenas criaturas funcionais neste ou naquele campo específicos. Apresentar os alunos à literatura é uma forma de torná-los mais humanos, não no sentido mais "filosófico" ou "metafísico" do termo, mas justamente no sentido "bruto": o ser humano, uma vez integrado à sociedade, tem na linguagem não somente uma forma efetiva e eficiente, na maior parte das vezes, de se

\footnotetext{
${ }^{17}$ Carta de Felipe Pimenta.

${ }^{18}$ Carta de Silas Sampaio Garcia.
} 
comunicar objetivamente, mas principalmente de vivenciar aquilo que não existe fora do campo da linguagem, fora desse mundo abstrato-concreto. A literatura faz essa passagem entre a comunicação e a integração do que está além, faz a ponte entre a pura expressão de sentimentos via linguagem e a moderação dos sentimentos através da linguagem, eliminando a barreira equivocada entre aquilo que é "útil" e aquilo que é "não útil". Ensinar literatura é, portanto, criar um espaço para o "não útil" lado a lado com tudo o que, apesar de taxado como "útil", mostra-se tantas vezes "inútil" para simplesmente ser humano. ${ }^{19}$

Afirmei, no início deste texto, que se tratava de um trabalho de autoria coletiva, e que, a ler minha carta aos alunos, preferi selecionar trechos das cartas que eles mesmos haviam escrito. Este trabalho recompõe, em grande parte, o que se sucedeu naquelas aulas, e se constitui, a bem ver, num manifesto. Ao final daquele ciclo de aulas houve, no entanto, um verdadeiro encerramento: a leitura de uma outra carta, publicada no "Painel do Leitor" daquele mesmo jornal, apenas dois dias após a publicação do artigo anterior. Não a li naquele momento em que foi publicada, nem logo depois; por isso, quando a encontrei, quase por acaso, num momento em que buscava pelo artigo citado, encarei-a como se estivesse diante de um achado. Era um texto muito curto, provavelmente editado pelo jornal. Tão curto quanto incisivo. Seu autor - e esse fora o motivo maior de espanto - era o professor Luiz Dantas, responsável por me apresentar Dostoiévski e Balzac, já no meu primeiro semestre cursando Letras na UNICAMP, e depois tantos outros autores e textos, durante o convívio que tivemos. Não há aluno que não se lembre do professor Dantas com carinho. Não há como deixar de admirá-lo por sua discrição aliada à erudição - características difíceis de conciliar, mas que encontravam nele seu verdadeiro ponto de equilíbrio. Também por isso, por sua timidez elegante, que tanto nos cativava, o tom de indignação de sua carta me causava surpresa. Mas era sobretudo pelo que afirmava que se fazia notar. Peço licença a ele, em sua memória, para tomar como nossas as suas palavras finais:

Acreditar no caráter fecundador e subversivo da literatura, mesmo nas piores condições, é lutar por um mínimo de luz, para que a barbárie não se torne absolutamente dominante. Não há luz de verdade nas fogueiras acesas ao longo do tempo, onde os livros foram queimados. [DANTAS, L., 200o] ${ }^{20}$

${ }^{19}$ Carta de Fernanda Capraro de Toledo.

${ }^{20}$ Luiz Dantas foi Diretor do IEL-UNICAMP, entre 1999 e 2003. 


\section{Gagliardi - 347 \\ REFERÊNCIAS BIBLIOGRÁFICAS}

BIZZOCCHI, Aldo. "Repensando o ensino da literatura". Publicado em "Tendências e Debates", Folha de São Paulo, 10/07/2000.

DANTAS, Luiz. "Com ou sem literatura". Publicado em "Painel do Leitor", Folha de São Paulo, 12/07/2000.

“Linguagens, Códigos e suas Tecnologias. (PCN+)". In: http://portal.mec.gov.br.

Cartas escritas em sala de aula pelos seguintes alunos, na ordem em que aparecem: Mateus Ramos Lourenço, João Henrique Lara Ganança, Daiane Walker Araujo, Alex Mazzanti Júnior, Fernanda Capraro de Toledo, Julia Garcia, Flávia Capraro de Toledo, Nara Lasevicius Carreira, Luana Barossi, Felipe Pimenta e Silas Sampaio Garcia. 